\title{
BMJ Open Periodontitis in early and chronic rheumatoid arthritis: a prospective follow-up study in Finnish population
}

\author{
Leena Äyräväinen, ${ }^{1}$ Marjatta Leirisalo-Repo, ${ }^{2}$ Antti Kuuliala, ${ }^{3}$ Kirsi Ahola, ${ }^{1}$ \\ Riitta Koivuniemi, ${ }^{2}$ Jukka H Meurman, ${ }^{1}$ Anna Maria Heikkinen ${ }^{1}$
}

To cite: Äyräväinen L, Leirisalo-Repo M, Kuuliala A, et al. Periodontitis in early and chronic rheumatoid arthritis: a prospective followup study in Finnish population. BMJ Open 2017;7:e011916.

doi:10.1136/bmjopen-2016011916

- Prepublication history for this paper is available online. To view these files please visit the journal online (http://dx.doi.org/10.1136/ bmjopen-2016-011916).

Received 20 March 2016 Revised 15 December 2016 Accepted 19 December 2016

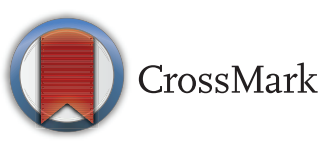

${ }^{1}$ Department of Oral and Maxillofacial Diseases, University of Helsinki, Helsinki, Finland

${ }^{2}$ Department of Rheumatology, University of Helsinki and Helsinki University Hospital, Helsinki, Finland

${ }^{3}$ Department of Bacteriology and Immunology, University of Helsinki and Helsinki University Hospital, Helsinki, Finland

Correspondence to Dr Leena Äyräväinen; leena.ayravainen@Helsinki.fi

\section{ABSTRACT}

Objectives: To investigate the association between rheumatoid arthritis (RA) and periodontitis with special emphasis on the role of antirheumatic drugs in periodontal health.

Design: Prospective follow-up study. Patients with early untreated RA and chronic active RA were examined at baseline and 16 months later. Controls were examined once.

Settings and participants: The study was conducted in Finland from September 2005 to May 2014 at the Helsinki University Hospital. Overall, 124 participants were recruited for dental and medical examinations: 53 were patients with early diseasemodifying antirheumatic drug (DMARD) naive RA (ERA), 28 were patients with chronic RA (CRA) with insufficient response to conventional DMARDs. After baseline examination, patients with ERA started treatment with synthetic DMARDs and patients with CRA with biological DMARDs. Controls were 43 agematched, gender-matched and community-matched participants.

Outcome measures: Degree of periodontitis (defined according to the Center for Disease Control and Prevention and the American Academy of Periodontology). Prevalence of periodontal bacteria (analysed from plaque samples), clinical rheumatological status by Disease Activity Score, 28-joint count (DAS28), function by Health Assessment Questionnaire (HAQ) and treatment response by European League Against Rheumatism (EULAR) criteria.

Results: Moderate periodontitis was present in $67.3 \%$ of patients with ERA, $64.3 \%$ of patients with CRA and $39.5 \%$ of control participants $(p=0.001)$. Further, patients with RA had significantly more periodontal findings compared with controls, recorded with common periodontal indexes. In the re-examination, patients with RA still showed poor periodontal health in spite of treatment with DMARDs after baseline examination. The prevalence of Porphyromonas gingivalis was higher in patients with ERA with periodontal probing depth $\geq 4 \mathrm{~mm}$ compared with patients with CRA and controls. Antirheumatic medication did not seem to affect the results.

Conclusions: Moderate periodontitis was more frequent in patients with RA than in controls. Patients with ERA and CRA exhibited poorer periodontal health

\section{Strengths and limitations of this study}

- We included two well-characterised patient groups with rheumatoid arthritis (RA).

- This was a prospective follow-up study.

- Patients with RA in this study represent well Finnish patients with RA in general.

- The number of study participants was a limitation of the study.

- We examined the control participants only once.

parameters when compared with controls. There was no association between antirheumatic treatment and periodontal parameters.

\section{INTRODUCTION}

Periodontitis is a complex chronic inflammatory disease destroying tooth-supporting tissues with multifactorial aetiology, ${ }^{1-3}$ and it has been linked to diabetes, cardiovascular disease, adverse pregnancy outcomes, other diseases, such as chronic obstructive airways disease, chronic kidney disease, cognitive impairment, metabolic syndrome, some types of cancer and rheumatoid arthritis (RA). ${ }^{4}$ Periodontal diseases are highly prevalent and can affect up to $90 \%$ of the world population with varying degree of disease severity. ${ }^{5}$ Manifestation of periodontitis may vary from latent to active phases and the disease may finally lead to loss of teeth. RA is a chronic autoimmune disease with recurring disease cycles destroying, if untreated, the cartilage and bone in the joints and subsequently leading to loss of function and mobility. ${ }^{6}$ The pathogenesis of RA is still unknown but both genetic and environmental factors are involved. $^{7-10}$ The triggering factors of the disease are under current interest. ${ }^{11}$ To suppress active inflammation, the treatment of RA consists of the use of conventional synthetic disease-modifying antirheumatic drugs 
(DMARDs), biological DMARDs and low-dose oral glucocorticoids. Patients with RA have an increased risk for infections. In addition, the treatments, especially biological DMARDs, used to suppress the activity of RA are associated with increased risk of infections. ${ }^{12} 13$

Periodontitis seems to have an association with RA and it has even been suspected to be a triggering factor for RA eruption. ${ }^{14}{ }^{15}$ Bacterial cultures from subgingival pockets of patients with periodontitis have identified increased proportions of bacteria, such as Porphyromonas gingivalis, Bacteroides forsythus, Campylobacter rectus, Selenomonas noxia, Prevotella intermedia, Fusobacterium nucleatum and Aggregatibacter actinomycetemcomitans. ${ }^{16}{ }^{17}$ Recent studies suggest an association of oral bacterial infections and RA, most of which were evaluated by bacterial gene identification or serum titre measurement. ${ }^{14} 1819$

Susceptibility to periodontitis and RA shares similarities regarding genetic and other factors such as obesity, smoking and socioeconomic status. ${ }^{20} 21$ Periodontitis and RA are chronic inflammatory diseases with varying activity due to imbalance in the immune-inflammatory response; their severity and loss of function also increase with disease duration. ${ }^{18}$ Furthermore, both diseases have similarities in morphology and histopathology. ${ }^{22}$ Humoral immune response to oral bacteria has been suggested to be linked to the pathogenesis of RA. ${ }^{23}$ However, RA typically presents in middle-aged women whereas periodontitis affects patients of any age and gender, even adolescents. ${ }^{24} \mathrm{RA}$ is nevertheless an inflammatory autoimmune disease, ${ }^{9}$ while periodontitis is an immune-inflammatory disease of bacterial origin. ${ }^{25}$

Most of the previous studies on periodontitis and RA are cross-sectional and have focused on chronic RA (CRA) with analysis of clinical signs of periodontitis, or microbiological findings, and the treatment with DMARDs has not been well characterised or not mentioned at all. Therefore, we aimed to study prospectively periodontitis in well-characterised patients with RA before and after therapy with first synthetic DMARDs or first biological DMARD. We compared patients with early untreated RA before and after treatment with synthetic DMARDs and those with chronic active RA on synthetic DMARDs before and after treatment with biological DMARDs. We analysed the changes in periodontal and microbiological findings with respect to antirheumatic therapy during a follow-up. The hypothesis was that there indeed is an association between RA and periodontitis and that RA treatment affects periodontal disease.

\section{METHODS}

Study design

This was a prospective follow-up study on three groups of participants: (1) patients with early DMARD naive RA (ERA), (2) patients with CRA with inadequate response to synthetic DMARDs (CRA) and (3) population controls. We included patients with RA aged 18-70 years.
Edentulous patients were excluded. The patients underwent dental and rheumatological examinations before and after the start of synthetic DMARDs and biological DMARDs, respectively. The controls were examined once. According to the classification by Hartling et $a l^{26}$ the study design is interrupted time series. The dental and medical examinations were conducted from September 2005 to May 2014; twice in patients with RA, at baseline and after subsequent follow-up, mean 15.9 \pm 6.1 months, and once, at baseline, in age-matched and gender-matched controls living in the same geographical region. One rheumatologist and one dentist examined each patient independently and were blinded from each other for the rheumatological and periodontal condition. Patients with RA were examined by the rheumatologist according to our hospital protocol in the Department of Rheumatology in the Helsinki University Hospital. The same dentist examined all the patients throughout the study in the Department of Oral and Maxillofacial Diseases, in the University of Helsinki. The study was conducted according to the principles of the Declaration of Helsinki. All patients and control participants gave written informed consent to participate in the study.

\section{Study population}

Eighty-one patients with RA consisting 53 patients with ERA and 28 patients with CRA with insufficient response to synthetic DMARDs (CRA) were recruited for clinical dental and medical examinations from the Department of Rheumatology of the Helsinki University Hospital. Patients with RA were mostly women (85\% of ERA and $82 \%$ of CRA group), with a mean age $( \pm \mathrm{SD}) 51 \pm 15$ years in ERA and $52 \pm 11$ years in CRA cases. Patients with ERA had suffered from the RA symptoms for a mean of 10.4 \pm 17.1 months, and patients with CRA for 176 \pm 116.8 months, respectively. We recruited 43 agematched and gender-matched control participants living in the same geographical area with the mean age of 56 \pm 13 years. Among them, $88 \%$ were women. The controls had been recruited using Statistics Finland, the national population database. During the study one patient with CRA died, two patients with ERA moved away and one patients with CRA and four ERA cases did not participate in the follow-up study because of personal reasons (see figure 1).

\section{Clinical dental examinations}

All participants were examined at the Department of Oral and Maxillofacial Diseases, in the University of Helsinki, Finland. The same dentist examined all the patients throughout the study in the Department of Oral and Maxillofacial Diseases, in the University of Helsinki. Complete dental status was recorded clinically with help of bite-wing X-rays. Natural teeth were examined. Third molars and dental implants were excluded. Periodontal parameters were recorded according to the WHO recommendations. ${ }^{27}$ Periodontal probing depth 
Figure 1 Study protocol. CRA, chronic rheumatoid arthritis; ERA early rheumatoid arthritis; RA, rheumatoid arthritis.

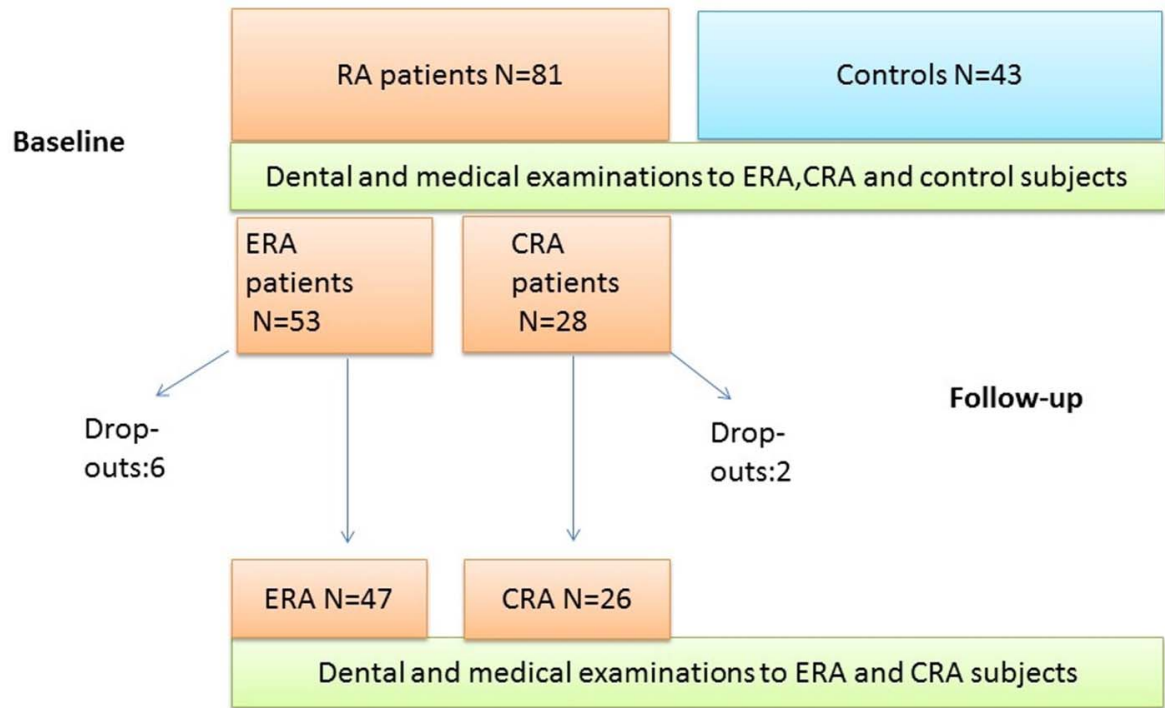

0.05\% thione E-peptone, 0.2\% washed Bacto Agar, 0.05\% thioglycolic acid, $0.05 \%$ L-cysteine-HCL, $1.0 \%$ Na glycerophosphate, $0.0005 \%$ phenylmercuric acetate, $0.0003 \%$ methylene blue, $0.024 \% \mathrm{CaCl}_{2} 6 \mathrm{H}_{2} 0,0.042 \% \mathrm{KCl}, 0.1 \%$ $\mathrm{NaCl}, 0.01 \% \mathrm{MgSO}_{4} 7 \mathrm{H}_{2} \mathrm{O}$. The samples were delivered for microbiological analyses in our hospital laboratory within 6 hours after sampling.

\section{Medical examinations}

Patients with RA were examined by a rheumatologist according to our hospital protocol. The number of swollen (66 joint count and 28 joint count) and tender (68 joint count and 28 joint count) joints were recorded. The patient's global assessment of disease activity (PGA) was based on a $100 \mathrm{~mm}$ visual analogue scale. Disease Activity Score (DAS28) was calculated from the number of tender and swollen joints (28-joint count), PGA and erythrocyte sedimentation rate (ESR). ${ }^{31}$

Medication in the case of patients with early untreated RA was introduced by the rheumatologist examining the patient. Medication in the case of patient with CRA was planned by the treating physician at the Department of Rheumatology. In each case, the treatments were started after the dental examination. The medications used by the patients during follow-up were collected from the patient files and by asking the patients during the follow-up examination.

\section{Periodontal bacteria}

Subgingival plaque samples were taken for analysing periodontal bacteria $A$. actinomycetemcomitans, $P$. gingivalis, $P$. intermedia, Tannerella forsythia, Parvimonas micra and C. rectus. Samples were pooled from the four to six deepest periodontal pockets at baseline and from the patients with RA again 1 year later. By sampling, sterile paper points were inserted in each chosen periodontal pocket. The paper points were then immediately transferred into a tube containing viability-maintaining microbiostatic medium, anaerobically prepared (Viability Medium Goteborg Aga (VMGA) III) containing 5\% bacto gelatine,

\section{Laboratory measurements}

Blood samples were analysed for plasma rheumatoid factor (RF) by immunoturbidimetric assay (Roche/ Hitachi Modular P. Roche Diagnostics, Mannheim, Germany), normal $<14 \mathrm{IU} / \mathrm{mL}$, plasma $\mathrm{C}$ reactive protein (CRP) by immunoturbidimetric assay (Roche/ Hitachi Modular P. Roche Diagnostics, Mannheim, Germany), normal $<3 \mathrm{mg} / \mathrm{L}$, ESR by automatic modified Westergren method of EDTA blood diluted with citrate. ${ }^{32}$ Serum antinuclear antibody (ANA) was measured by the 
indirect immunofluorescence technique on a HEp-2 cell substrate (Inova Diagnostics, San Diego, California, USA). The serum was initially screened at a 1:80 dilution, and positive samples were further diluted to 1:160, 1:320, $1: 640,1: 1280$ and 1:5120. A titre of $1: 320$ or higher was considered a positive result.

\section{Antirheumatic treatment}

After the baseline examinations, patients with ERA started treatment with synthetic DMARDs comprising methotrexate (MTX), leflunomide (LEF), sulfasalazine (SSZ) and hydroxychloroquine (HCQ) either as monotherapy or in different combinations. Monotherapy was used in $37.0 \%$ of patients with ERA (mostly MTX, two patients had LEF), double DMARD therapy (MTX+SSZ, MTX+HCQ SSZ+HCQ or combinations with LEF) in $39.1 \%$ and triple DMARD therapy (MTX+SSZ+HCQ) in $19.1 \%$ of patients with ERA. In addition, low-dose ( $\leq 10 \mathrm{mg}$ prednisolone) oral glucocorticoids were started in $28.3 \%$ of the patients with ERA. CRA cases started biological DMARDs consisting of tumour necrosis factor $\alpha$ (TNF- $\alpha$ ) inhibitors (such as adalimumab in 9/27 $(33.3 \%)$ of patients with CRA, etanercept in $17 / 27$ (63.0\%), golimumab in 2/27 $(7.4 \%)$ and certolizumab pegol in $1 / 27$ (3.7\%) of patients with CRA) or non-TNF- $\alpha$ biologicals such as interleukin-1 inhibitor (anakinra in $1 / 27(3.7 \%)$ of patients with CRA) or anti-B-cell agent (rituximab in 2/27 $(7.4 \%)$ of patients with CRA) mainly combined with MTX, 3 patients with CRA had LEF. Different biological DMARDs were used during the follow-up; in brief TNF- $\alpha$ inhibitor was used in $85.2 \%$ of patients with CRA and non-TNF- $\alpha$ biologicals in $7.4 \%$, respectively. Low-dose prednisolone was used by $74.1 \%$ patients with CRA. Intra-articular glucocorticoid injections and non-steroidal anti-inflammatory drugs (NSAIDs) were used if needed to improve physical function and quality of life.

\section{Questionnaires}

All the study participants filled out a structured questionnaire. Questions concerned general health and systemic medication, education, health habits (smoking, use of alcohol) as well as daily oral hygiene habits, dental visits, self-assessed oral health and oral symptoms. The questionnaire is a standard form at our clinic, and used in several other studies. ${ }^{33} 34$

\section{Statistical methods}

The results are given as medians with IQRs (25-75\%; non-parametric distribution) or in means with SDs (parametric distribution). Continuous variables were compared between groups with analysis of variance and Student's t-test when possible, or non-parametric Kruskal-Wallis and Mann-Whitney tests when comparing independent samples. The baseline and follow-up values were analysed with non-parametric Wilcoxon test comparing related samples. Categorical variables were compared between the groups with $\chi^{2}$ test and between baseline and follow-up values with McNemar's test. Binary logistic regression model was performed to establish odds for periodontitis according to variables such as RA (early and chronic), tooth brushing, smoking, gender and age. Statistical analyses were performed with SPSS V.22 and $\mathrm{p}<0.05$ was considered statistically significant.

\section{RESULTS}

RF was present in $79.2 \%$ of patients with ERA, $69.2 \%$ of patients with CRA and in 3\% of control individuals $(\mathrm{p}<0.001)$. CRA participants had suffered from RA for a mean of $176 \pm 116.8$ months while the duration of disease in patients with ERA was $10.4 \pm 17.1$ months $(\mathrm{p}<0.001)$. At baseline, ESR values were in median (IQR 25-75\%) 20 (11-34) $\mathrm{mm} /$ hour in ERA, 20 (9-46) $\mathrm{mm} /$ hour in CRA and $2(2-10) \mathrm{mm} /$ hour in the control group $(\mathrm{p}<0.001)$. CRP values were 6 (3-14) $\mathrm{mg} / \mathrm{L}$ in ERA, 18 (5-30) $\mathrm{mg} / \mathrm{L}$ in CRA and 2 (2-3) $\mathrm{mg} / \mathrm{L}$ in the control group $(\mathrm{p}<0.001)$, respectively.

Patients with RA had a history of hypertension, thyroid disease, bronchial asthma, depression, cancer and diabetes as comorbidities. Compared with patients with CRA and controls, the patients with ERA had more often asthma (19\% vs $0 \%$ in CRA, $5 \%$ in controls $(\mathrm{p}=0.046))$.

There were no statistically significant differences between the study participants with respect to age, gender, smoking, alcohol use and level of education. Background characteristics of the study groups are given in more detail in table 1.

Self-reported oral health habits are given in table 2. Control participants reported better oral hygiene habits, especially more frequent approximal tooth cleaning, when compared with patients with RA. At baseline, the patients with RA reported having received less periodontal treatments than controls, but in the re-examination mean 16 months later the number of patients with RA having periodontal treatment increased. The specific determination of profession (hygienist, dentist, periodontist) for periodontal treatment was not available from the patients' questionnaire.

Periodontal status parameters are given in table 3 . Periodontal findings in patients with RA differed significantly from the corresponding control cases in values of VPI, BOP, $\mathrm{PD} \geq 4 \mathrm{~mm}, \quad \mathrm{AL}<3 \mathrm{~mm}, \quad \geq 3 \mathrm{~mm}<5 \mathrm{~mm}$, $\mathrm{AL} \geq 5 \mathrm{~mm}$ and PIBI. Sixty seven per cent of the patients with ERA and $64 \%$ of the patients with CRA had moderate periodontitis at the time of entry to the study. In the controls, the corresponding frequency was $39.5 \%$ as given in table 3. CRP values in patients with ERA with periodontitis (mild, moderate or severe) were in median with IQR 6 (3-14) $\mathrm{mg} / \mathrm{L}$, in CRA participants with periodontitis 17 (5-30) $\mathrm{mg} / \mathrm{L}$ and in controls 2 (2-2) $\mathrm{mg} / \mathrm{L}$ $(p<0.001)$ at baseline. However, in ERA cases with severe periodontitis CRP values were 7 (3-15) $\mathrm{mg} / \mathrm{L}$, in patients with CRA with severe periodontitis CRP values 
Table 1 Background characteristics of the study groups at baseline

\begin{tabular}{|c|c|c|c|c|}
\hline & ERA $(N=53)$ & CRA $(\mathrm{N}=28)$ & Controls $(\mathrm{N}=43)$ & p Value \\
\hline Women, N (\%) & $45(85)$ & $23(82)$ & $38(88)$ & 0.758 \\
\hline Age (years), mean $\pm S D$ & $51 \pm 15$ & $52 \pm 11$ & $56 \pm 13$ & 0.160 \\
\hline Number of teeth, median (IQR) & $27(23-28)$ & $27(22-28)$ & $27(25-28)$ & 0.628 \\
\hline Rheumatoid factor present (\%) & $42(79.2)$ & $18(69.2)$ & $3(8.1)^{*}$ & $<0.001$ \\
\hline Disease duration (months), mean $\pm S D$ & $10.4 \pm 17.1$ & $176 \pm 116.8$ & & $<0.001 \dagger$ \\
\hline ESR (mm/hour), median (IQR) & $20(11-34)$ & $20(9-46)$ & $2(2-10)^{*}$ & $<0.001$ \\
\hline CRP (mg/L), median (IQR) & $6(3-14)$ & $18(5-30)$ & $2(2-3)^{*}$ & $<0.001$ \\
\hline DAS28, median (IQR) & $4.0(3.2-4.8)$ & $4.1(3.0-4.9)$ & & 0.974 \\
\hline \multicolumn{5}{|l|}{ Education, $\mathrm{N}(\%) \ddagger$} \\
\hline Lower & $20(37.7)$ & $9(36.0)$ & $16(61)$ & 0.174 \\
\hline Secondary & $27(50.9)$ & $12(48.0)$ & $6(23.1)$ & \\
\hline Higher & $6(11.3)$ & $4(16.0)$ & $4(15.4)$ & \\
\hline \multicolumn{5}{|l|}{ Smoking, N (\%) } \\
\hline Never & $35(66.0)$ & $23(82.1)$ & $36(83.7)$ & \\
\hline Former & $7(13.0)$ & $2(7.0)$ & $1(2.0)$ & \\
\hline Current & $11(21.0)$ & $3(11.0)$ & $6(14.0)$ & 0.197 \\
\hline \multicolumn{5}{|l|}{ Alcohol use, N (\%) } \\
\hline Seldom/none & $28(52.8)$ & $12(42.9)$ & $13(30.2)$ & \\
\hline Monthly/weekly & $25(47.2)$ & $16(57.1)$ & $30(69.8)$ & 0.084 \\
\hline
\end{tabular}

${ }^{*} \mathrm{~N}=37$, missing data from six control participants, no visit to laboratory.

tp value obtained by non-parametric Kruskal-Wallis test comparing patients with ERA and CRA.

¥Missing data: 3 patients with CRA and 17 control participants for unknown reasons.

$p$ Values by cross-tabulating with $\chi^{2}$ across the study groups.

CRA, chronic rheumatoid arthritis; CRP, serum C reactive protein level; DAS28, Disease Activity Score (28-joint count); ERA, early

rheumatoid arthritis; ESR, erythrocyte sedimentation rate; N, number of patients.

$32(21-42) \mathrm{mg} / \mathrm{L}$ and in the one control patient with severe periodontitis $2 \mathrm{mg} / \mathrm{L}(\mathrm{p}=0.029)$, respectively. At follow-up examination, the periodontal status in patients with RA was similar to the baseline.

Table 4 gives results from the cultivation of the periodontal bacteria. At baseline periodontal bacteria were more frequently detected in the patients with ERA compared with patients with CRA, and after the follow-up, the prevalence of periodontal bacteria in CRA group was further diminished. In RA, $P$. gingivalis was observed only in patients with ERA ( $\mathrm{p}=0.043$, table 4$)$.

Figure 2 shows the results for $P$. gingivalis in the participants who had $\mathrm{PD} \geq 4 \mathrm{~mm}$. The culture for $P$. gingivalis was positive in 11 participants $(21.2 \%)$ in the ERA group at baseline, compared with 3 participants $(7.0 \%)$ in the controls $(\mathrm{p}=0.009)$. In patients with CRA no $P$. gingivalis-positive cases were found.

In patients with ERA, synthetic DMARDs were instituted first after the clinical and dental examinations. There were no statistically significant changes in the periodontal parameters between baseline and follow-up examination (table 3). The patients with CRA examined at baseline continued their baseline synthetic DMARD (s) on which a biological DMARD was added on after the baseline examination. Despite the biological DMARD, no statistically significant difference was found in the periodontal parameters either in the patients with CRA during the follow-up (table 3).

Of periodontopathic bacteria, $P$. gingivalis was less frequently cultivated in patients with ERA at follow-up examination, but with respect to other microbes, there were no statistically significant chances during the follow-up (table 4).

After multivariate analysis for odds of periodontal disease, age, gender, smoking and tooth brushing were not statistically significantly associated with periodontitis. Significant association was observed between CRA versus controls, OR 5.3 (95\% CI 1.1 to 25.6; $\mathrm{p}=0.044$ ) and ERA versus controls, OR 3.6 (95\% CI 1.1 to 11.6; $\mathrm{p}=0.036$ ). Figures are given in table 5 .

\section{DISCUSSION}

\section{Periodontal health in RA}

The main result in our study was that periodontal health indeed was poorer in patients with RA in general compared with population controls. Nearly $80 \%$ of patients with ERA and $85 \%$ of patients with CRA suffered from periodontitis vs $40 \%$ of controls at the baseline of this study. These findings confirmed earlier observations by Wolff $e t a l,{ }^{35}$ and Ranade and Doiphode. ${ }^{36}$ The poorer periodontal health could be the result of a weakened immune defence in the host due to RA and further, increase in systemic inflammation may initiate or enhance the severity of periodontitis as pointed out by Payne $e t a l .{ }^{37}$ Periodontitis in turn may have an impairing influence on RA treatment response. Although our results are based only a limited number of patients with RA, they can be applied to Finnish patients with RA in general, as our study populations are in line with two 
Table 2 Self-reported oral health habits during the study

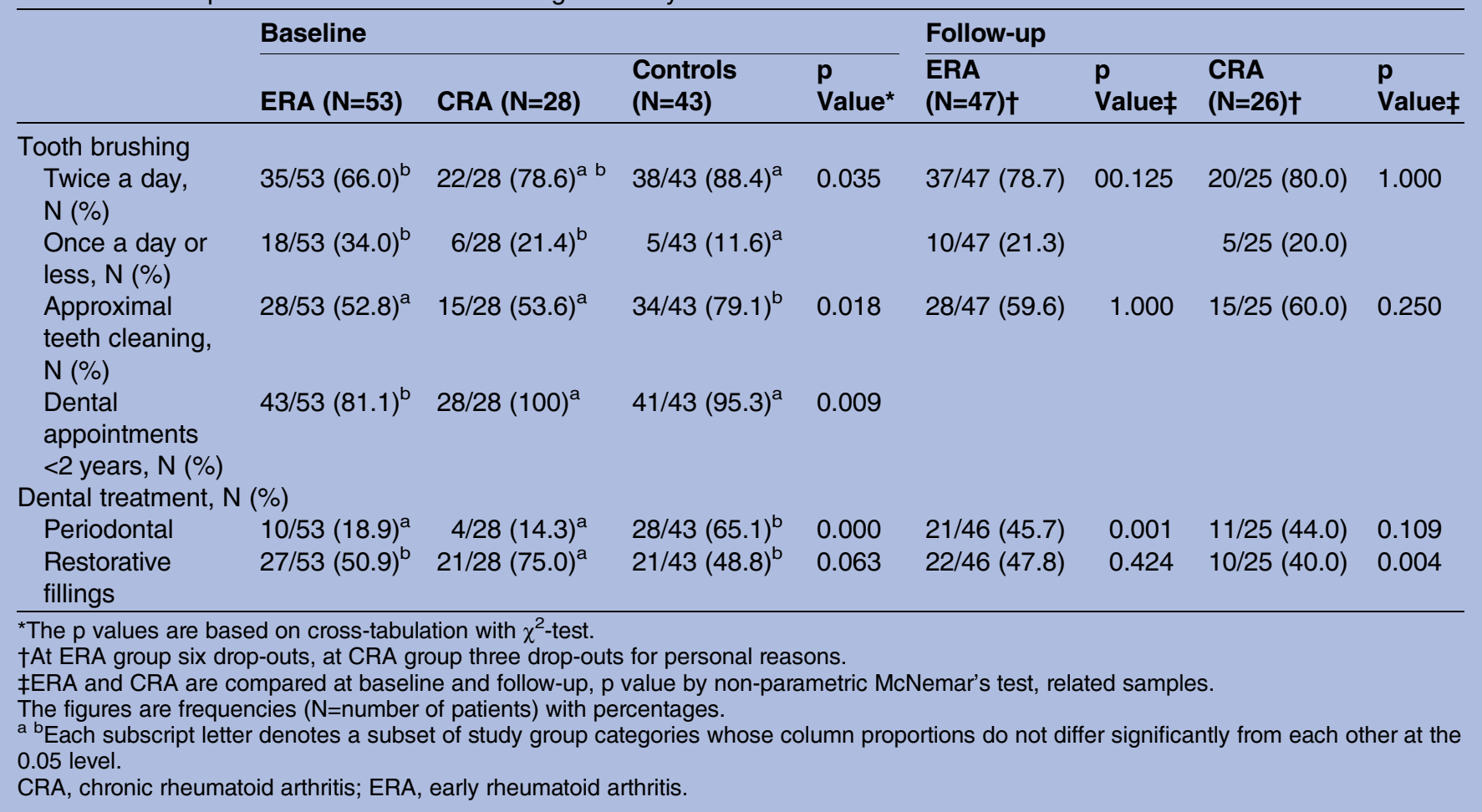

recent reports from Finland. Rannio et $a \hat{l}^{8}$ described all patients with DMARD-naïve early RA $(n=310)$ treated at Jyväskylä Central Hospital rheumatology outpatient clinic between 2008 and 2011. The centre covers rheumatology care in the healthcare district with a population of 275 000. The demographic data of our patients with ERA are comparable with those of the Jyväskylä cohort: mean age 51 vs 60 years, women $81 \%$ vs $69 \%$, duration of symptoms 10 vs 6 months, disease activity (DAS28) 4.0 vs 4.3 . As to the patients with CRA starting biological treatments, we can compare our patients with CRA with those reported from the National Register for Biologic Treatment in Finland, which is a prospective cohort study designed to monitor the effectiveness and safety of biological drugs in the treatment of rheumatic diseases. The register covers about $70 \%$ of patients with RA treated with biologics in Finland. Recently, Aaltonen $e t a l^{39}$ reported data collected from year 2003 onwards from this register. The demographic data of our patients with CRA are comparable with those reported from the The Finnish Register of Biological Treatment (ROB-FIN) registry: mean age 52 vs 54 years, women $82 \%$ vs $79 \%$, disease duration 14.6 vs 11 years, disease activity (DAS28) 4.1 vs 4.4 before the start of biological DMARD.

\section{$\mathrm{RA}$ and periodontitis}

An association between RA and periodontitis has been suggested in several earlier studies. ${ }^{19}{ }^{40-44}$ Of special interest is that patients with early untreated RA had even worse periodontal health compared with patients with CRA, and further patients with RA both in early and chronic stages suffered more frequently particularly from moderate periodontitis when compared with population controls in our study. The frequencies of periodontitis in RA and control populations vary from study to study. According to a recent review with meta-analysis, the risk for periodontitis in RA versus controls is $1.13 .^{45}$ The prevalence of periodontitis in the US population aged over 30 years is $47 \%$. The risk factors include smoking, age, dental hygiene, minority status and socioeconomic status. ${ }^{46}$

Many authors, such as Loos, ${ }^{47}$ have suggested that periodontal lesions may be the origin for daily bacteraemia and even raise systemic inflammation reflected in markers such as CRP. In our study, patients with CRA with severe periodontitis had higher CRP values compared with corresponding ERA participants. Interestingly, during the follow-up, no improvement could be observed in periodontal status among the patients with RA in either group.

\section{RA and $P$. gingivalis}

An association between infection at early arthritis phase and the subsequent development of chronic rheumatic complications has been discussed previously as reviewed by Leirisalo-Repo. ${ }^{48}$ The presence of $P$. gingivalis in patients with ERA, as observed in our study among the patients with $\mathrm{PD} \geq 4 \mathrm{~mm}$, may be a combining link between periodontal disease and RA. Rutger Persson ${ }^{49}$ suggested that $P$. gingivalis infection through citrullination has a role in RA. And further, Mikuls et $a \bar{l}^{0}$ reported that periodontal inflammation with $P$. gingivalis 
Table 3 Periodontal parameters at baseline and after follow-up in study groups

\begin{tabular}{|c|c|c|c|c|c|c|c|c|}
\hline & $\begin{array}{l}\text { Baseline } \\
\text { ERA N=52 }\end{array}$ & $\begin{array}{l}\text { Follow-up } \\
\text { ERA N=46 }\end{array}$ & p Value* & $\begin{array}{l}\text { Baseline } \\
\text { CRA N=28 }\end{array}$ & $\begin{array}{l}\text { Follow-up } \\
\text { CRA N=26 }\end{array}$ & p Value* & Controls $\mathrm{N}=43$ & p Valuet \\
\hline \multicolumn{9}{|l|}{ Medication $\ddagger$} \\
\hline DMARD monotherapy & 0 & $17 / 46(37.0 \%)$ & & $8 / 28(28.6 \%)$ & 0 & & & \\
\hline Double DMARD therapy & 0 & $18 / 46(39.1 \%)$ & & $11 / 28(39.3 \%)$ & 0 & & & \\
\hline Triple DMARD therapy & 0 & 9/46 (19.6\%) & & $7 / 28(25.0 \%)$ & 0 & & & \\
\hline DMARD(s)+TNF inhibitor & 0 & 0 & & 0 & 23/27 (85.2\%) & & & \\
\hline DMARD(s)+non-TNF inhibitor & 0 & 0 & & 0 & $3 / 27(11.1 \%)$ & & & \\
\hline \multicolumn{9}{|l|}{ Periodontal degree, $\mathrm{N}(\%) \S$} \\
\hline Mild & 0 & $1(2.2)$ & 0.297 & $2(7.1)$ & $1(4.0)$ & 0.398 & $1(2.3)$ & 0.001 \\
\hline Moderate & $35(67.3)$ & $34(73.9)$ & & 8 (64.3) & $14(56.0)$ & & $17(39.5)$ & \\
\hline Severe & $6(11.5)$ & $5(10.9)$ & & $4(14.3)$ & $3(12.0)$ & & $1(2.3)$ & \\
\hline Number of teeth & $27(23-28)$ & $27(22-28)$ & 0.024 & $27(22-28)$ & 27 (22-28) & 0.317 & $27(25-28)$ & 0.628 \\
\hline VPI per cent sites, median (IQR) & $12(5-25)$ & $8(4-20)$ & 0.076 & $9(5-19)$ & $8(3-19)$ & 0.467 & $5(2-11)$ & 0.020 \\
\hline BOP per cent sites, median (IQR) & $15(10-26)$ & $13(6-21)$ & 0.124 & $9(5-19)$ & $8(3-22)$ & 0.903 & $4(2-8)$ & 0.000 \\
\hline $\mathrm{PD} \geq 1$ sites with $\geq 4 \mathrm{~mm}, \mathrm{~N}(\%)$ & $45(86.5)$ & $43(95.6)$ & 0.083 & 25 (89.3) & $21(84.0)$ & 0.564 & $28(65.1)$ & 0.013 \\
\hline $0-1$ site with $\geq 6 \mathrm{~mm}$ & 49 (94.2) & $43(95.6)$ & 0.564 & $24(85.7)$ & $22(88.0)$ & 0.317 & $42(97.7)$ & 0.131 \\
\hline$\geq 2$ sites with $\geq 6 \mathrm{~mm}$ & $3(5.8)$ & $2(4.4)$ & 0.366 & $4(14.3)$ & $3(12.0)$ & 1.000 & $1(2.3)$ & 0.067 \\
\hline$<2$ teeth with $\geq 5 \mathrm{~mm}$ & $39(75.0 \%)$ & $37(80.4 \%)$ & & $23(82.1 \%)$ & $21(80.8 \%)$ & & $40(93.0 \%)$ & \\
\hline$\geq 2$ teeth with $\geq 5 \mathrm{~mm}$ & $13(25.0 \%)$ & $9(19.6 \%)$ & & $5(17.9 \%)$ & $5(19.2 \%)$ & & $3(7.0 \%)$ & \\
\hline$A L<3$ & $5(9.6)$ & $3(6.7)$ & 1.000 & $2(7.1)$ & $5(20.0)$ & 0.083 & $14(32.6)$ & 0.004 \\
\hline$\geq 3<5 \mathrm{~N}(\%)$ & $47(90.4)$ & 42 (93.3) & 1.000 & 26 (92.9) & $20(80.0)$ & 0.083 & $29(67.4)$ & 0.004 \\
\hline$\geq 5$ & $22(42.3)$ & $21(46.7)$ & 0.257 & $10(35.7)$ & $8(32.0)$ & 0.317 & 8 (18.6) & 0.045 \\
\hline PIBI, median (IQR) & $10(3-18)$ & $9(9-19)$ & 0.907 & $5(3-15)$ & $4(1-16)$ & 0.856 & $1(0-3)$ & 0.000 \\
\hline
\end{tabular}

In VPI and BOP index used 4 sites at every tooth

§Definition for degree of periodontal disease according to the Center for Disease Control and Prevention and the American Academy of Periodontology (CDC/AAP; Page and Eke, 2007), ${ }^{8}$ mild periodontitis. ${ }^{29}$

${ }^{*} p$ Value by non-parametric Wilcoxon test comparing related samples at baseline and follow-up examination.

tp Value by cross-tabulation with $\chi^{2}$ comparing all study groups at baseline $p$ value by non-parametric Kruskal-Wallis test.

fDMARD monotherapy: mostly MTX, 2 patients had LEF; double therapy: MTX+SSZ, MTX+HCQ, SSZ+HCQ, or combinations with LEF; triple therapy: MTX+SSZ+HCQ; TNF inhibitor:

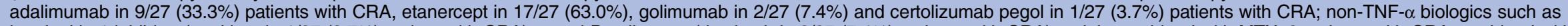
interleukin-1 inhibitor (anakinra in 1/27 (3.7\%) patient with CRA) or anti-B-cell agent (rituximab in 2/27 (7.4\%) patients with CRA) mainly combined with MTX, 3 patients with CRA combined with LEF.

AL, clinical attachment loss; BOP, Bleeding on Probing index; CRA, chronic rheumatoid arthritis; DMARD, disease-modifying antirheumatic drug; ERA, early rheumatoid arthritis ; HCQ,

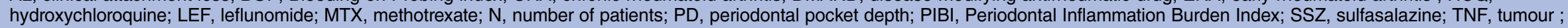
necrosis factor; VPI, Visual Plaque Index. 
Table 4 Prevalence of periodontopathic bacteria at baseline and after follow-up in study participants with $\mathrm{PD} \geq 4 \mathrm{~mm}$

\begin{tabular}{|c|c|c|c|c|c|c|c|}
\hline & $\begin{array}{l}\text { ERA } \\
(\mathrm{N}=46) \\
\text { Baseline }\end{array}$ & $\begin{array}{l}\text { CRA (N=25) } \\
\text { Baseline }\end{array}$ & $\begin{array}{l}\text { Controls } \\
(\mathrm{N}=27)\end{array}$ & p Value ${ }^{*}$ & $\begin{array}{l}\text { ERA (N=43) } \\
\text { After } \\
\text { follow-up }\end{array}$ & $\begin{array}{l}\text { CRA (N=21) } \\
\text { After } \\
\text { follow-up }\end{array}$ & p Value $†$ \\
\hline \multicolumn{8}{|l|}{ Medication } \\
\hline DMARD monotherapy & 0 & $8 / 28(28.6 \%)$ & & & $\begin{array}{l}17 / 46 \\
(37.0 \%)\end{array}$ & 0 & \\
\hline Double DMARD therapy & 0 & $11 / 28(39.3 \%)$ & & & $\begin{array}{l}18 / 46 \\
(39.1 \%)\end{array}$ & 0 & \\
\hline Triple DMARD therapy & 0 & 7/28 (25.0\%) & & & 9/46 (19.6\%) & 0 & \\
\hline $\begin{array}{l}\text { DMARD(s)+TNF } \\
\text { inhibitorf }\end{array}$ & 0 & 0 & & & 0 & $\begin{array}{l}23 / 27 \\
(85.2 \%)\end{array}$ & \\
\hline $\begin{array}{l}\text { DMARD(s)+non-TNF } \\
\text { inhibitors§ }\end{array}$ & 0 & 0 & & & 0 & $3 / 27(11.1 \%)$ & \\
\hline \multicolumn{8}{|l|}{ Bacteria } \\
\hline A.a N (\%) & $4(8.7 \%)$ & 0 & $5(18.5 \%)$ & 0.074 & $2(4.9 \%)$ & 0 & 0.298 \\
\hline P.g & $11(23.9 \%)$ & 0 & $2(7.4 \%)$ & 0.12 & $7(17.1 \%)$ & 0 & 0.043 \\
\hline P.i & 15 (32.6\%) & $8(33.3 \%)$ & $10(37.0 \%)$ & 0.925 & 19 (46.3\%) & $5(22.7 \%)$ & 0.054 \\
\hline T.f & $2(4.3 \%)$ & $1(4.2 \%)$ & 0 & 0.550 & $1(2.4 \%)$ & $1(4.5 \%)$ & 0.248 \\
\hline P.m & $12(26.1 \%)$ & $6(25.0 \%)$ & $4(14.8 \%)$ & 0.514 & $10(24.4 \%)$ & $3(13.6 \%)$ & 0.329 \\
\hline C.r & $2(4.3 \%)$ & $1(4.2 \%)$ & 0 & 0.550 & $3(7.3 \%)$ & 0 & 0.199 \\
\hline
\end{tabular}

${ }^{*} \mathrm{p}$ Values by cross-tabulation with $\chi^{2}$.

tp Values obtained with non-parametric Kruskal-Wallis test comparing independent samples (study groups: baseline-follow-up).

fDMARD monotherapy: mostly MTX, 2 patients had LEF; double therapy: MTX+SSZ, MTX+HCQ, SSZ+HCQ, or

combinations with LEF; triple therapy: MTX+SSZ+HCQ; TNF inhibitor: adalimumab in 9/27 (33.3\%) patients with CRA, etanercept in 17/27

$(63.0 \%)$, golimumab in $2 / 27(7.4 \%)$ and certolizumab pegol in $1 / 27(3.7 \%)$ patients with CRA).

§Non-TNF- $\alpha$ biologics such as interleukin-1 inhibitor (anakinra in 1/27 (3.7\%) patient with CRA) or anti-B-cell agent

(rituximab in $2 / 27(7.4 \%)$ patients with CRA) mainly combined with MTX, 3 patients with CRA combined with LEF.

A.a, Aggregatibacter actinomycetemcomitans; C.r, Campylobacter rectus; CRA chronic rheumatoid arthritis; DMARD, disease-modifying

antirheumatic drug; ERA, early rheumatoid arthritis; HCQ, hydroxychloroquine; LEF, leflunomide; MTX, methotrexate; N number of

participants; PD, periodontal pocket depth; P.g, Porphyromonas gingivalis; P.i, Prevotella intermedia; P.m, Parvimonas micra; SSZ,

sulfasalazine; T.f, Tannerella forsythia; TNF, tumour necrosis factor.

may modify the autoreactivity of RA. Bacterial culture methods were used in this study for practical reasons, being routine in the hospital laboratory. The association of oral pathogens and periodontal activity might have been higher if we had performed bacterial gene identification by real-time PCR or measured serum antibodies to oral pathogens.

\section{Antirheumatic medication and oral health}

We also focused on the effect of the use of antirheumatic medication on periodontal parameters. Therefore, we included patients with early untreated RA at baseline. After the examination, the patients started treatment with synthetic DMARDs. Patients with CRA on the other hand had suffered from the disease for about 14 years and because of insufficient response to synthetic DMARDs, treatment with biological DMARDs was started. Both synthetic and biological DMARDs were, if necessary, combined with glucocorticoids or NSAIDs to suppress the disease symptoms and to improve quality of life.

Recently, Beeraka et $a \varphi^{51}$ reported an association between the use of corticosteroids and higher levels of AL and deepened periodontal pocket depth. We did not observe any statistical difference in periodontal parameters when comparing the baseline values to corresponding figures after the mean 16 months follow-up in the ERA and CRA groups. Our results on patients with ERA show that periodontitis was observed in patients with RA already in the early untreated phase and that conventional antirheumatic treatment did not enhance the inflammation or oral pathogenic microbes. This is in line with a previous study, where MTX had no effect on dental status. ${ }^{52}$

Most studies on the association between treatment of RA and severity of periodontitis have focused on biological DMARDs. A recent meta-analysis included four reports on the effect of anti-TNF- $\alpha$ therapy in patients with RA. ${ }^{53}$ In three out of the four reports, the treatment was suppressing periodontal inflammation. Three more publications have reported the suppressive effect of adalimumab, tocilizumab and rituximab on periodontitis. ${ }^{54-56}$ Contrary to these findings, periodontal parameters remained stable during the 6-month treatment of 18 patients with RA with various anti-TNF- $\alpha$ therapies. ${ }^{57}$ Our results show that biological DMARDs can be used in patients with chronic active RA, as they do not worsen periodontitis in these patients. In fact, there was a trend for improvement in pocket depths in the CRA group.

However, while periodontitis does not usually need pharmacological treatment, mechanical periodontal treatment is required time after time. ${ }^{15}$

\section{Health habits}

Patients with RA in both groups reported poorer approximal teeth cleaning and less periodontal dental 


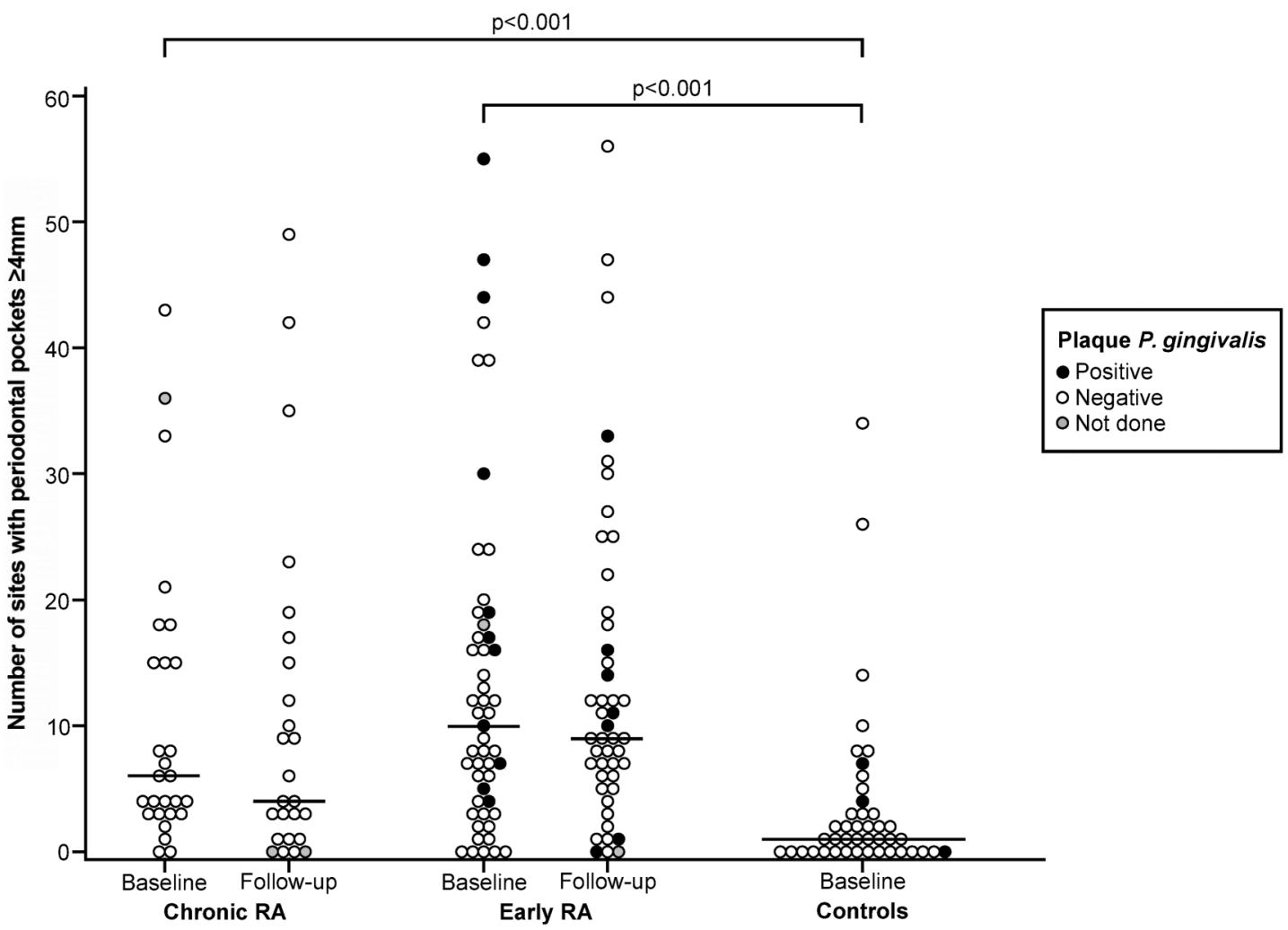

Figure 2 Number of sites with $\mathrm{PD} \geq 4 \mathrm{~mm}$ and periodontopathic bacteria in RA groups and controls. The symbols show individual participants with group medians denoted by horizontal lines. The groups were compared using Mann-Whitney test. The dental plaque culture for Porphyromonas gingivalis was positive in 11 participants $(21.2 \%)$ in the early RA group at baseline, compared with 3 participants $(7.0 \%)$ in the control group $\left(p=0.009, \chi^{2}\right.$ test). The number of cases positive for $P$. gingivalis in chronic RA group was 0 . PD, periodontal pocket depth; RA, rheumatoid arthritis.

\begin{tabular}{|c|c|c|}
\hline Variable & OR $(95 \% \mathrm{Cl})$ & p Value \\
\hline \multicolumn{3}{|l|}{ Group } \\
\hline CRA & $5.3(1.1$ to 25.6$)$ & 0.044 \\
\hline ERA & $3.6(1.1$ to 11.6$)$ & 0.036 \\
\hline Controls & 1 & \\
\hline Brushing at least twice daily & 0.7 (0.4 to 6.2$)$ & 0.657 \\
\hline Smoking (current) & $0.3(0.06$ to 1.5$)$ & 0.134 \\
\hline Sex (male) & 2.7 (0.3 to 24.5$)$ & 0.368 \\
\hline Age (per year) & $1.1(1.0$ to 1.1$)$ & 0.011 \\
\hline
\end{tabular}

treatment compared with the population controls (see table 2). Impaired oral health habits rather than weakened immune defence could partly explain the differences in plaque accumulation and gingival inflammation in patients with RA. This also reflects in higher frequencies of VPI and BOP sites. However, the weakened manual dexterity may have a role in oral hygiene habits and thus these patients need special attention in controlling oral hygiene with suitable individual dental hygiene equipment combined with proper periodontal treatment.
Against all expectations smoking or use of alcohol did not seem to affect the results. This might be explained by the fact that there is a decreased prevalence of smoking among Finnish population in general. ${ }^{58}$

\section{Strengths and limitations}

The strengths of our study were the prospective follow-up study of two well-characterised patient groups with RA, the inclusion of control participants and the homogeneous ethnicity of the population. All participants were from the population base of the Helsinki University Hospital with more than 1.5 million inhabitants. Our study patients are representative of the patients with RA in Finnish population. ${ }^{38} 39$

The weakness was the fairly small number of patients although we recruited all eligible patients during nearly 10 years (2005-2014). Furthermore, for practical reasons, it was not possible to conduct follow-up examination in the controls.

To conclude, our study revealed poor periodontal health in patients with early and CRA compared with population controls. The periodontal parameters were throughout higher in patients with early RA compared with patients with RA with long disease history. We did not observe any effect of synthetic or biological DMARDs on the periodontal health parameters. Taking 
into account the inflammatory burden of periodontitis combined with the challenge of RA disease itself, these patients should be under supervised oral health with emphasis on periodontist. By offering these patients relevant periodontal treatment, it is possible to reduce oral inflammatory burden. This is of importance when treating patients with autoimmune disease, such as RA, and using biological DMARDs with increased risk of infection as a side effect. However, the results with a follow-up design should be confirmed in a larger study which includes control population, patients in the preclinical phase of RA, those with early RA at the time of diagnosis and those patients with RA who have failed conventional DMARDs and are starting treatment with biologicals. Thus, in future studies, periodontal health parameters should be recorded and diagnosed if found, in addition to targeting the RA treatment to remission or to low disease activity; periodontitis should also be actively treated and the treatment response should be evaluated with respect to the activity of RA regularly.

Contributors $L A ̈$ is the main investigator in this study which is part of her $\mathrm{PhD}$ education. ML-R and RK recruited and performed the rheumatological examination of the patients. KA was the main contributor of the dental data collection. AK was involved in data acquisition, analyses and preparing the manuscript. ML-R, JHM and AMH were the principal investigators involved in study design, analyses and in critical evaluation of the manuscript.

Funding The study was supported by grants from the Helsinki University Hospital Research Funds (EVO-grants TYH5231, TYH2008232, TYH2011115, TYH2013328, TYH2013334, TYH2014225, TYH2015119), Finska

Läkaresällskapet and from the Medical Society of Finland.

Competing interests None declared.

Ethics approval The study was approved by the Independent Review Board of the Helsinki and Uusimaa Hospital District (no 240/2004, date 16.6.2004).

Provenance and peer review Not commissioned; externally peer reviewed.

Data sharing statement No additional data are available.

Open Access This is an Open Access article distributed in accordance with the Creative Commons Attribution Non Commercial (CC BY-NC 4.0) license, which permits others to distribute, remix, adapt, build upon this work noncommercially, and license their derivative works on different terms, provided the original work is properly cited and the use is non-commercial. See: http:// creativecommons.org/licenses/by-nc/4.0/

\section{REFERENCES}

1. Stabholz A, Soskolne WA, Shapira L. Genetic and environmental risk factors for chronic periodontitis and aggressive periodontitis. Periodontol 2000 2010;53:138-53.

2. Genco RJ, Borgnakke WS. Risk factors for periodontal disease. Periodontol 2000 2013;62:59-94.

3. Phipps KR, Stevens VJ. Relative contribution of caries and periodontal disease in adult tooth loss for an $\mathrm{HMO}$ dental population. $J$ Public Health Dent 1995;55:250-2.

4. Chapple IL, Wilson NH. Manifesto for a paradigm shift: periodontal health for a better life. Br Dent $J$ 2014;216:159-62.

5. Pihlstrom BL, Michalowicz BS, Johnson NW. Periodontal diseases. Lancet 2005;366:1809-20.

6. Schett G, Teitelbaum SL. Osteoclasts and arthritis. J Bone Miner Res 2009;24:1142-6.

7. Gregersen PK, Silver J, Winchester RJ. The shared epitope hypothesis. An approach to understanding the molecular genetics of susceptibility to rheumatoid arthritis. Arthritis Rheum 1987;30:1205-13.
8. Hinks A, Eyre S, Barton A, et al. Investigation of genetic variation across the protein tyrosine phosphatase gene in patients with rheumatoid arthritis in the UK. Ann Rheum Dis 2007;66:683-6.

9. Wellcome Trust Case Control Consortium. Genome-wide association study of 14,000 cases of seven common diseases and 3,000 shared controls. Nature 2007;447:661-78.

10. Stolt P, Bengtsson C, Nordmark B, et al., EIRA study group (2005) Quantification of the influence of cigarette smoking on rheumatoid arthritis: results from a population based case-control study, using incident cases. Ann Rheum Dis 2003:62:835-41.

11. Hogeboom C. Peptide motif analysis predicts alphaviruses as triggers for rheumatoid arthritis. Mol Immunol 2015;68:465-75.

12. Ruderman EM. Overview of safety of non-biologic and biologic DMARDs. Rheumatology (Oxford) 2012;51(Suppl 6):vi37-43.

13. Ramiro S, Gaujoux-Viala C, Nam JL, et al. Safety of synthetic and biological DMARDs: a systematic literature review informing the 2013 update of the EULAR recommendations for management of rheumatoid arthritis. Ann Rheum Dis 2014;73:529-35.

14. Detert J, Pischon N, Burmester GR, et al. The association between rheumatoid arthritis and periodontal disease. Arthritis Res Ther 2010;12:218.

15. Araújo VMA, Melo IM, Lima V. Relationship between periodontitis and rheumatoid arthritis: review of the literature. Mediators Inflamm 2015;2015:259074.

16. Umeda $\mathrm{M}$, Tominaga $\mathrm{Y}, \mathrm{He} \mathrm{T}$, et al. Microbial flora in the acute phase of periodontitis and the effect of local administration of minocycline. J Periodontol 1996;67:422-7.

17. Tanner A, Maiden MF, Macuch PJ, et al. Microbiota of health gingivitis and initial periodontitis. J Clin Periodontol 1998;25:85-98.

18. de Smit M, Westra J, Vissink A, et al. Periodontitis in established rheumatoid arthritis patients: a cross-sectional clinical, microbiological and serological study. Arthritis Res Ther 2012;14:R222.

19. Scher JU, Ubeda C, Equinda M, et al. Periodontal disease and the oral microbiota in new-onset rheumatoid arthritis. Arthritis Rheum 2012;64:3083-94.

20. Klareskog L, Stolt $\mathrm{P}$, Lundberg $\mathrm{K}$, et al. A new model for an etiology of rheumatoid arthritis: smoking may trigger HLA-DR (shared epitope)-restricted immune reactions to autoantigens modified by citrullination. Arthritis Rheum 2006;54:38-46.

21. de Hair MJ, Landewé RB, van de Sande MG, et al. Smoking and overweight determine the likelihood of developing rheumatoid arthritis. Ann Rheum Dis 2013;72:1654-8.

22. Culshaw S, McInnes IB, Liew FY. What can the periodontal community learn from the pathophysiology of rheumatoid arthritis? $J$ Clin Periodontol 2011;38(Suppl 11):106-13.

23. Rosenstein ED, Greenwald RA, Kushner LJ, et al. Hypothesis: the humoral immune response to oral bacteria provides a stimulus for the development of rheumatoid arthritis. Inflammation 2004;28:311-18.

24. Heikkinen AM, Pajukanta R, Pitkäniemi J, et al. The effect of smoking on periodontal health of 15- to 16-year-old adolescents. $J$ Periodontol 2008;79:2042-7.

25. Kinane DF, Preshaw PM, Loos BG. Host-response: understanding the cellular and molecular mechanisms of hostmicrobial interactions - consensus of the Seventh European Workshop on

Periodontology. J Clin Periodontol 2011;38:44-8.

26. Hartling L, Bond K, Santaguida PL, et al. Testing a tool for the classification of study designs in systematic reviews of interventions and exposures showed moderate reliability and low accuracy. J Clin Epidemiol 2011;64:861-71

27. Oral Health Surveys Basic Methods. 4th edn. Geneva: World Health Organization, 1997;4-52.

28. Page RC, Eke PI. Case definitions for use in population-based surveillance of periodontitis. J Periodontol 2007;78:1387-99.

29. Eke PI, Page RC, Wei L, et al. Update of the case definitions for population-based surveillance for periodontitis. J Periodontol 2012;83:1449-54.

30. Lindy $\mathrm{O}$, Suomalainen $\mathrm{K}$, Mäkelä $\mathrm{M}$, et al. Statin use is associated with fewer periodontal lesions: a retrospective study. BMC Oral Health 2008;8:16.

31. Prevoo MLL, vant't Hof MA, Kuper $\mathrm{HH}$, et al. Modified disease activity scores that include twenty-eight-joint counts: development and validation in a prospective longitudinal study of patients with rheumatoid arthritis. Arthritis Rheum 1995;38:44-8.

32. Reference and Selected Procedure for the Erythrocyte Sedimentation (ESR) Test, Approved Standard (NCCLS Document) 4th ed. Edition, 2000.

33. Helenius LM, Hietanen JH, Helenius I, et al. Focal sialadenitis in patients with ankylosing spondylitis and spondyloarthropathy: a comparison with patients with rheumatoid arthritis or mixed connective tissue disease. Ann Rheum Dis 2001;60:744-9. 
34. Helenius LM, Hallikainen D, Helenius I, et al. Clinical and radiographic findings of the temporomandibular joint in patients with various rheumatic diseases. A case-control study. Oral Surg Med Oral Pathol Oral Radiol Endod 2005;99:455-63.

35. Wolff B, Berger T, Frese C, et al. Oral status in patients with early rheumatoid arthritis: a prospective, case-control study. Rheumatology (Oxford) 2014;53:526-31.

36. Ranade SB, Doiphode S. Is there a relationship between periodontitis and rheumatoid arthritis? J Indian Soc Periodontol 2012;16:22-7.

37. Payne JB, Golub LM, Thiele GM, et al. The link between periodontitis and rheumatoid arthritis: a periodontist's perspective. Curr Oral Health Rep 2015;2:20-9.

38. Rannio T, Asikainen J, Kokko A, et al. Early remission is a realistic target in a majority of patients with DMARD-naive rheumatoid arthritis. J Rheumatol 2016:43:699-706.

39. Aaltonen KJ, Joensuu JT, Virkki L, et al. Rates of serious infections and malignancies among patients with rheumatoid arthritis receiving either tumor necrosis factor inhibitor or rituximab therapy. $J$ Rheumatol 2015;42:372-8.

40. Pischon N, Pischon T, Kröger J, et al. Association among rheumatoid arthritis, oral hygiene, and periodontitis. J Periodontol 2008;79:979-86.

41. de Pablo P, Dietrich T, McAlindon TE. Association of periodontal disease and tooth loss with rheumatoid arthritis in the US population. J Rheumatol 2008;35:70-6.

42. Dissick A, Redman RS, Jones M, et al. Association of periodontitis with rheumatoid arthritis: a pilot study. J Periodontol 2010;81:223-30.

43. Joseph R, Rajappan S, Nath SG, et al. Association between chronic periodontitis and rheumatoid arthritis: a hospital-based case-control study. Rheumatol Int 2013;33:103-9.

44. Mikuls TR, Payne JB, Yu F, et al. Periodontitis and Porphyromonas gingivalis in patients with rheumatoid arthritis. Arthritis Rheum 2014;66:1090-100.

45. Fuggle NR, Smith TO, Kaul A, et al. Hand to mouth: a systematic review and meta-analysis of the association between rheumatoid arthritis and periodontitis. Front Immunol 2016;7:80.

46. Bingham COIII, Moni M. Periodontal disease and rheumatoid arthritis: the evidence accumulates for complex pathobiologic interactions. Curr Opin Rheumatol 2013;25:345-53.
47. Loos BG. Systemic markers of inflammation in periodontitis. J Periodontol 2005;76:2106-15.

48. Leirisalo-Repo M. Early arthritis and infection. Curr Opin Rheumatol 2005;17:433-9.

49. Rutger Persson G. Rheumatoid arthritis and periodontitisinflammtory and infectious connections. Review of the literature. J Oral Microbiol 2012;4:11829.

50. Mikuls TR, Thiele GM, Deane KD, et al. Porphyromonas gingivalis and disease-related autoantibodies in individuals at increased risk of rheumatoid arthritis. Arthritis Rheum 2012;64:3522-30.

51. Beeraka SS, Natarajan K, Patil R, et al. Clinical and radiological assessment of effects of long-term corticosteroids therapy on oral health. Dent Res J 2013;10:666-73.

52. Pers JO, Saraux A, Pierre R, et al. Anti-TNF- $\alpha$ immunotherapy is associated with increased gingival inflammation without clinical attachment loss in subjects with rheumatoid arthritis. $J$ Periodontol 2008;79:1645-51.

53. Han JY, Reynolds MA. Effect of anti-rheumatic agents on periodontal parameters and biomarkers of inflammation: a systematic review and meta-analysis. J Periodontal Implant Sci 2012;42:3-12.

54. Kobayashi T, Yokoyama T, Ito S, et al. Periodontal and serum protein profiles in patients with rheumatoid arthritis treated with tumor necrosis factor inhibitor adalimumab. J Periodontol 2014;85:1480-8.

55. Kobayashi T, Okada M, Ito S, et al. Assessment of interleukin-6 receptor inhibition therapy on periodontal condition in patients with rheumatoid arthritis and chronic periodontitis. $J$ Periodontol 2014;85:57-67.

56. Coat J, Demoersman J, Beuzit S, et al. Anti-B lymphocyte immunotherapy is associated with improvement of periodontal status in subjects with rheumatoid arthritis. J Clin Periodontol 2015;42:817-23.

57. Savioli C, Ribeiro AC, Fabri GM, et al. Persistent periodontal disease hampers anti-tumor necrosis factor treatment response in rheumatoid arthritis. J Clin Rheumatol 2012;18:180-4.

58. Borodulin K, Vartiainen $\mathrm{E}$, Peltonen $\mathrm{M}$, et al. Forty-year trends in cardiovascular risk factors in Finland. Eur $J$ Public Health 2015;25:539-46. 